\title{
Accelerated Episodic Luteinizing Hormone Release Accompanies Blunted Progesterone Regulation in PCOS-like Female Rhesus Monkeys (Macaca Mulatta) Exposed to Testosterone during Early-to-Mid Gestation
}

\author{
David H. Abbott ${ }^{\text {a d }}$ Sarah H. Vepraskas ${ }^{\text {a }}$ Teresa H. Horton ${ }^{\mathrm{e}}$ \\ Ei Terasawa ${ }^{b, d}$ Jon E. Levine ${ }^{c, d}$ \\ ${ }^{a}$ Department of Obstetrics and Gynecology, University of Wisconsin, Madison, WI, USA; ${ }^{b}$ Department of Pediatrics, \\ University of Wisconsin, Madison, WI, USA; ' $D$ Department of Neuroscience, University of Wisconsin, Madison, WI, USA; \\ ${ }^{\mathrm{d}}$ Wisconsin National Primate Research Center, University of Wisconsin, Madison, WI, USA; ${ }^{e}$ Department of Neurobiology \\ and Physiology, Institute for Neuroscience, Center for Reproductive Science, Northwestern University, Evanston, IL, USA
}

\section{Keywords \\ Androgens - Developmental origins of health and disease . \\ Gonadal steroids - Gonadotropin-releasing hormone . \\ Gonadotropins · Hypothalamus · Primates · Testosterone}

\begin{abstract}
Background/Aims: Ovarian theca cell hyperandrogenism in women with polycystic ovary syndrome (PCOS) is compounded by androgen receptor-mediated impairment of estradiol and progesterone negative feedback regulation of episodic luteinizing hormone $(\mathrm{LH})$ release. The resultant $\mathrm{LH}$ hypersecretion, likely the product of accelerated episodic release of gonadotropin-releasing hormone $(\mathrm{GnRH})$ from the median eminence of the hypothalamus, hyperstimulates ovarian theca cell steroidogenesis, enabling testosterone $(T)$ and androstenedione excess. Prenatally androgenized (PA) female monkeys exposed to fetal male levels of $T$ during early-to-mid gestation, when adult, demonstrate PCOS-like traits, including high $\mathrm{T}$ and LH levels. This study tests the hypothesis that progesterone resistance-associated accelera-
\end{abstract}

tion in episodic $\mathrm{LH}$ release contributes to PA monkey $\mathrm{LH}$ excess. Methods: A total of 4 PA and 3 regularly cycling, healthy control adult female rhesus monkeys of comparable age and body mass index underwent (1) a $10 \mathrm{~h}$, frequent intravenous sampling assessment for LH episodic release, immediately followed by (2) IV infusion of exogenous GnRH to quantify continuing pituitary LH responsiveness, and subsequently (3) an SC injection of a progesterone receptor antagonist, mifepristone, to examine LH responses to blockade of progesterone-mediated action. Results: Compared to controls, the relatively hyperandrogenic PA females exhibited $\sim 100 \%$ increase $(p=0.037)$ in LH pulse frequency, positive correlation of LH pulse amplitude ( $p=0.017)$ with androstenedione, $\sim 100 \%$ greater increase $(p=0.034)$ in acute $(0-10 \mathrm{~min}) \mathrm{LH}$ responses to exogenous $\mathrm{GnRH}$, and an absence $(p=0.008)$ of modest LH elevation following acute progesterone receptor blockade suggestive of diminished progesterone negative feedback. Conclusion: Such dysregulation of LH release in PCOS-like monkeys implicates impaired feedback control of episodic release of hypothalamic GnRH reminiscent of PCOS neuroendocrinopathy.

\section{KARGER}

(C) 2018 S. Karger AG, Basel

E-Mail karger@karger.com

www.karger.com/nen
David H. Abbott, PhD

Department of Obstetrics and Gynecology and the Wisconsin National Primate Research Center, University of Wisconsin, 1223 Capitol Court

Madison, WI 53715 (USA)

E-Mail abbott@primate.wisc.edu 


\section{Introduction}

Polycystic ovary syndrome (PCOS) is the most prevalent endocrinopathy in women's health, contributing not only substantially increased risk of infertility and hirsutism, but also increased risk of type 2 diabetes mellitus, cardiovascular disease, and endometrial cancer [1]. Increasing evidence implicates neural androgen receptor (AR) $[2,3]$, dysregulation of hypothalamic gonadotropin-releasing hormone $(\mathrm{GnRH})$, and pituitary luteinizing hormone (LH) secretion, as well as enhanced ovarian responsiveness to LH in its pathogenesis [4-7]. PCOS diagnosis derives from a reproductive phenotype, including 2 out of 3 of the following criteria: androgen excess, infrequent or absent ovulatory menstrual cycles, and polycystic ovary morphology [8]. Any single diagnostic trait can therefore be absent when a diagnosis is made.

High frequency episodic release of $\mathrm{GnRH}$ from the hypothalamus typifies many women with PCOS $[9,10]$ and enables both LH hypersecretion contributing to ovarian hyperandrogenism [11] and relative follicle stimulating hormone (FSH) deficiency encouraging ovarian follicular arrest $[12,13]$. Such gonadotropin imbalance is consistent with recent identification of PCOS risk genes implicated in the regulation of pituitary gonadotropin release $[5,14]$ as well as functional clinical studies demonstrating diminished negative feedback regulation on LH, and probably GnRH release, mediated by estradiol and progesterone [3, 15]. Exaggerated episodic release of LH is a pre-pubertal characteristic of adolescent girls with hyperandrogenism [16-19], including absent nocturnal slowing of LH release episodes [20] and $~ 50 \%$ incidence of diminished progesterone-mediated negative feedback on LH [21]. Together, these LH traits are suggestive of pre-PCOS neuroendocrine pathogenesis already established in the immature female hypothalamus.

Not surprisingly, therefore, developmental programming has proved a successful strategy for designing the most comprehensive, experimentally induced animal models for PCOS, initiated by prenatally androgenized (PA) female rhesus monkeys [22-24]. Progressively increasing evidence of fetal $\mathrm{T}$ exposure in daughters of women with PCOS implicates an analogous pathogenic mechanism in women [25-28]. Fetal PA monkeys exhibit LH hypersecretion within weeks of early-to-mid gestation exposure to fetal male testosterone ( $\mathrm{T}$ ) levels [29]. Their LH excess persists into adulthood and is accompanied by ovarian hyperandrogenism, intermittent and absent ovulatory menstrual cycles, as well as polycystic ovaries [30], together with PCOS-typical metabolic sequelae: increased incidence of type 2 diabetes, abdominal adiposity, adipogenic constraint, and hyperlipidemia [31, 32]. Emulating LH traits in women with PCOS, elevated LH levels in PA monkeys show resistance to negative feedback suppression from either exogenous estradiol [33] or gonadotropin hyperstimulated, endogenous ovarian hormone release [34]. In a separate study, adult female rhesus monkeys with naturally occurring hyperandrogenism also exhibit elevated LH levels and accompanying PCOS-like reproductive dysfunction [35, 36], together with genital biomarkers indicative of fetal T excess [36]. Numerous studies have since demonstrated fetal $\mathrm{T}$ or dihydrotestosterone (DHT) programming of LH hypersecretion as a consequence of elevated episodic release of GnRH/LH in PA adult female sheep [37$39]$, rats [40, 41], and mice [42, 43]. Such elevated LH is associated with insensitivity to estradiol- or progesterone-mediated negative feedback [37, 43-45], likely mediated within the hypothalamus $[46,47]$. Such neural origins for LH excess, and diminished LH sensitivity to estradiol/progesterone-mediated negative feedback, however, have yet to be demonstrated in PCOS-like, female nonhuman primates.

It is critical that these PCOS-like neuroendocrine characteristics are established in nonhuman primates since non-primate neuroendocrine regulation of $\mathrm{GnRH}$ fundamentally differs from that in primates. For example, unlike non-primates, there is little circadian signal control of preovulatory $\mathrm{GnRH}$ surges [48], fetal androgen excess elimination of estradiol-induced ovulatory LH surges [49] and peri-natal androgen programming of $\mathrm{GnRH}$ negative feedback [24], while gonadectomized male monkeys with ovarian transplants exhibit cycle ovulatory cycles [50]. Moreover, before puberty, there is a strong central component of GnRH inhibition in primates that consistently involves gamma-amino butyric acid (GABA) as a neural substrate, and has no counterpart in non-primates [51]. Evidence for fetal androgen excess programming of PCOS-like GnRH regulation in female rhesus monkeys would therefore, for the first time, implicate a neural developmental window in female primates, including humans, as vulnerabilities for PCOS-like conversion, and would open the door to development of selective pharmaceutical rescue $[3,52]$ with high likelihood of translation.

Consequently, this study was designed to test the hypothesis that gonadotropin dysfunction in PA adult female monkeys is a consequence of increased frequency of $\mathrm{GnRH}$ release from the hypothalamus, thus implicating neuroendocrine programming in a PA nonhuman pri- 
mate model for PCOS at a hypothalamic neuronal (LH pulse frequency) location as well as at a pituitary gonadotrope (LH pulse amplitude) location. Quantitative assessment of episodic LH release in the systemic circulation was used as biomarker for $\mathrm{GnRH}$ release, given the reliable association between $\mathrm{GnRH}$ and $\mathrm{LH}$ episodic release in adult female rhesus monkeys $[53,54]$. Increased pituitary $\mathrm{LH}$ responsiveness to exogenous $\mathrm{GnRH}$ was re-confirmed and acute LH responses to a single injection of the progesterone receptor $(\mathrm{PR})$ antagonist, mifepristone, were analyzed for evidence of diminished progesterone negative feedback on $\mathrm{LH}$.

\section{Materials and Methods}

\section{Ethics Statement}

The Institutional Animal Care and Use Committee of the Graduate School of the University of Wisconsin-Madison approved all procedures used in the study, and the care and housing of the monkeys was in accordance with the recommendations of the Guide for the Care and Use of Laboratory Animals and Animal Welfare Act with its subsequent amendments.

\section{Animals}

The 7 adult female rhesus monkeys (Macaca mulatta) used in this study were maintained at the Wisconsin National Primate Research Center at the University of Wisconsin-Madison (WNPRC). The animals were housed in female pairs, under controlled lighting (12 h of light (daytime), $12 \mathrm{~h}$ of darkness (nighttime), lights on at $06: 00 \mathrm{~h})$ and temperature $\left(22^{\circ} \mathrm{C}\right)$, according to standard protocol $[55,56]$. They were fed Purina monkey chow (product No. 5038, Ralston Purina, St Louis, MO, USA) with occasional supplementation of fresh fruits. This formulation of monkey chow provides $70 \%$ of calories as carbohydrate, $13 \%$ as fat, and $17 \%$ as protein. Age and body mass index (body weight [kg]/crown-rump length $\left.{ }^{2}\left[\mathrm{~m}^{2}\right]\right)$ [57] of both female groups were comparable (Table 1). Four of the female monkeys were exposed to gestational T excess by SC injection of their dams with $10 \mathrm{mg}$ testosterone propionate starting on gestational days 40-44 for 1535 consecutive days (early-to-mid gestation, PA). Only 4 of the 14 previously described PA monkeys were studied [31] because they previously exhibited high T levels [58], increased anogenital distance (an anatomical biomarker of early-to-mid gestational T exposure) [59], and intermittent menstrual cycles [58] compared to controls (Table 1), while remaining healthy. The 3 control female monkeys in this study were not exposed to exogenous $T$ excess in utero, were not otherwise manipulated during gestation by other investigators or colony management at WNPRC, and were selected from healthy adult monkeys exhibiting regular menstrual cycles. For some of the female monkeys in this study, somatometric measures, basal levels of ovarian and pituitary hormones, and menstrual cycle duration were previously reported [30, 60-63]. Those reported here were obtained specifically for this study. Baseline blood samples providing serum for hormone analyses were obtained from animals accustomed to using a tabletop restraint without anesthesia [61].

Increased LH Pulse Frequency in PCOSLike Monkeys
All experiments were performed between September and May, to avoid seasonal oligo- or anovulation [61]. Experiments 1 and 2 were carried out during days $1-5$ of the same menstrual cycle or during the same period of anovulation, while Experiment 3 was performed during a different menstrual cycle or anovulatory period.

\section{Experiment 1: Quantitative Assessment of Episodic}

LH Release

All monkeys were adapted to the jacket-tether apparatus for several weeks before catheter implantation surgery (see below). This training included 3 or more separate sessions for each animal. To obtain samples from a remote site without disturbing the research subjects, monkeys were implanted with indwelling catheters in their saphenous vein. The catheter was exteriorized through a tether-jacket system and was connected to a swivel device at the top of each cage through an opaque plastic curtain into an adjacent part of the room, that is, the paired animals were kept in semi-isolation out of visual contact with researchers, but were visible through video camera connection to a monitor from which observers could view their behaviors. To assess between group differences in circulating $\mathrm{LH}, 0.2 \mathrm{~mL}$ blood samples were collected at 10-min intervals for $10 \mathrm{~h}$ (06:00-16:00 h). Daytime hours were chosen for examination of LH episodic release to avoid potential nighttime slowing of $\mathrm{LH}$ pulse frequency [64]. After each blood sampling, plasma was separated by centrifugation, and blood cells from the previous sample were resuspended in sterile saline and re-injected into the monkey. An indwelling catheter made from SILASTIC brand tubing (Dow Corning Corp, Midland, MI, USA) was inserted into the saphenous vein, under isoflurane anesthesia, 1 day before the start of each experiment, as described previously $[65,66]$. The catheter was exteriorized through the back, and an extension of the catheter was passed through a cloth jacket with a tether-swivel system, allowing normal movement by the monkey. The catheter extension was connected to a 3-way stopcock for blood sampling and injection. The patency of the catheter was maintained by constant infusion of $0.5 \mathrm{~mL} / \mathrm{h}$ sterile saline containing $5 \mathrm{IU} /$ $\mathrm{mL}$ heparin until the initiation of blood sampling after surgery.

LH pulses were detected using the PULSAR algorithm [67]. Pulses of $\mathrm{LH}$ were determined using parameters similar to those previously reported [68], with modified cut-off criteria for G1, G2, G3, G4, and G5 of 3.0, 2.5, 1.5, 1.2, and 1.0 sd, respectively. The inter-assay standard variation for LH radioimmunoassay was $y=(2.67 x+2.17] / 100$, modified from that previously described [68].

Experiment 2: Exogenous GnRH Stimulation of LH Release

To examine pituitary responsiveness to human GnRH (L-7134, Sigma Chemical Company, St. Louis, MO, USA), plasma samples were collected from all 7 monkeys involved in Experiment 1, using identical sampling methods. After $10 \mathrm{~h}$ of sampling for episodic $\mathrm{LH}$ release assessment (see above), $2 \mu \mathrm{g} / \mathrm{kg} \mathrm{GnRH}$ (in $0.5 \mathrm{~mL}$ sterile saline) was administered through the indwelling IV catheter at 16:00 $\mathrm{h}$, and 10-min blood sampling was continued for an additional $2 \mathrm{~h}$ until 18:00 h (lights off). The GnRH test was designed to assess pituitary gonadotropin responses to exogenous GnRH [51], but not ovarian responses to $\mathrm{GnRH}$-stimulated gonadotropin release. To minimize the total period of sampling, we did not examine the $\mathrm{LH}$ response to vehicle. 
Experiment 3: LH Response to PR Antagonism

Each monkey was injected IM with $5 \mathrm{mg} / \mathrm{kg}$ mifepristone (PR antagonist; donated by Roussel-UCLAF, Romainville, France) in $0.2 \mathrm{~mL}$ sterile sesame oil immediately after a blood sample $(0.5 \mathrm{~mL})$ was withdrawn at $0 \mathrm{~h}(07: 00-08: 00 \mathrm{~h})$, and successive $0.5 \mathrm{~mL}$ daytime blood samples were withdrawn hourly from 3 to $10 \mathrm{~h}$ following injection. Serum was assayed for bioactive LH (bioLH). The dose of mifepristone was comparable to that used to examine gonadotropin responses to acute PR blockade in women [69], and the timing of blood sampling accommodated both attainment of maximum mifepristone levels in blood (at least $2 \mathrm{~h}$ post-injection) [70] and brain [71], as well as maintenance of blood levels (half-life of $\sim 25-30 \mathrm{~h}$ ) [72].

\section{Hormone Assays}

All gonadotropin and steroid hormone assays were performed in the WNPRC Hormone Assay Services Laboratory, as previously described $[55,73,74]$. Serum concentrations of immunoactive LH and FSH (Experiments 1 and 2) were determined by in-house radioimmunoassays [55], and those for bioLH (Experiment 3) were determined by mouse Leydig cell bioassay using the rhLH-RP1 reference preparation [29]. All assays were validated for rhesus monkeys. Detection limits, as well as intra- and inter-assay CoVs, were respectively as follows: $\mathrm{LH} 0.15 \mathrm{ng} / \mathrm{mL}, 7$ and 13\%; FSH $0.08 \mathrm{ng} / \mathrm{mL}, 3$ and 13\%; bioLH $0.30 \mathrm{ng} / \mathrm{mL}, 9$ and $18 \%$.

For steroid hormone analyses, plasma samples underwent extraction and subsequent analysis on a QTRAP 5500 quadruple linear ion trap mass spectrometer ( $\mathrm{AB}$ Sciex) equipped with an atmospheric pressure chemical ionization source (LC-MS/ MS), as previously described [74]. A sample of $10 \mu \mathrm{L}$ was injected onto a Phenomenex Kinetex 2.6u C18 100A, $100 \times 2.1 \mathrm{~mm}$ column (Phenomenex) for separation using a mobile phase: water with $1 \%$ formic acid (Solution A) and acetonitrile with $1 \%$ formic acid (Solution B), at a flow rate of $200 \mu \mathrm{L} / \mathrm{min}$. After $3 \mathrm{~min}$, Solution B was incrementally increased to $100 \%$ over the course of the next $17 \mathrm{~min}$. Mass spectrometer results were generated in positive-ion mode with the following optimized voltages: corona discharge current, $3 \mathrm{~V}$; entrance potential, $10 \mathrm{~V}$. The source temperature was $500^{\circ} \mathrm{C}$. The gas settings were as follows: curtain gas, 30 psi; nebulizing gas, 20 psi; collisionally activated dissociation gas, medium. Quantitative results were recorded as multiple reaction monitoring (MRM) area counts after determination for the response factor for each compound and internal standard. Each steroid had a MRM used for quantitation and 1 or 2 additional MRMs as qualifiers. The lower limits of quantitation were $7.0 \mathrm{pg} / \mathrm{mL}$ for $\mathrm{T}$, androstenedione, progesterone and dehydroepiandrosterone (DHEA); $2.7 \mathrm{pg} / \mathrm{mL}$ for estradiol $\left(\mathrm{E}_{2}\right)$ and estrone $\left(\mathrm{E}_{1}\right)$. Linearity was $r>0.9990$ and the curve fit was linear with $1 / x$ weighting. None of the compounds of interest were detected in blank or double blank samples. Intra-assay LC-MS/MS coefficients of variation were determined from a pool of human serum: $\mathrm{E}_{2}, 4 \%$; $\mathrm{E}_{1}, 12 \%$; progesterone, $4 \%$; DHEA, $13 \%$; androstenedione, $8 \%$; $\mathrm{T}, 11 \%$.

\section{Statistical Analyses}

All results are expressed as mean \pm SEM and log transformed to achieve homogeneity of variance and to increase linearity when appropriate [75] prior to $t$ test (baseline parameters) or appropriately designed analysis of variance with 1 between-subject factor (types of female monkeys) and 2 within-subject factors (treatment and time) with Tukey's post hoc means comparisons. Numbers of LH pulses and immediate (0-10 min) LH responses to GnRH injection were analyzed by the Mann Whitney U test. Least mean square regression analyses were used to examine parameter associations. Statistical significance was determined as $p<0.05$.

\section{Results}

\section{Baseline Characteristics}

Adult female PA and control monkeys were in their late reproductive years with comparable average to overweight body mass index (Table 1) without obesity (>12 kg body weight). While $50 \%$ of PA females exhibited intermittent ovulatory cycles, in contrast to none of the controls (Table 1), there were no other menstrual cycle parameter differences between the $2 \mathrm{fe}$ male groups. PA females, during the early-to-mid follicular phase of a menstrual cycle or a duration of anovulation, exhibited modest aspects of hyperandrogenism and hypersecretion of $\mathrm{LH}$, with trends toward elevated serum ratios for $\mathrm{T}$ to $\mathrm{E}_{2}(p=0.069)$ and serum $\mathrm{T}$ levels $(p=0.077)$, as well as an increased ratio of bioLH to immunoactive LH $(p=0.033)$, compared to controls (Table 1).

When all females were considered together, positive correlations were found between circulating $T$ and DHEA levels $(r=1.04, p=0.001)$, and between circulating $\mathrm{E}_{2}$ and progesterone levels $(r=1.06, p=0.008)$, as well as a positive trend between $\mathrm{T}$ and the ratio for bioactive to immunoactive LH $(r=0.81, p=0.088)$ and a negative trend between circulating $\mathrm{E}_{2}$ levels and menstrual cycle duration $(r=0.74, p=0.057)$. No other correlations were identified (Table 2 ).

\section{Experiment 1: Quantitative Assessment of Episodic}

\section{LH Release}

PA females exhibited an approximately $120 \%$ increase $(p=0.037)$ in the number of LH pulses/hour (pulse frequency) identified by the PULSAR algorithm compared to controls, with accompanying trends toward decreased inter-pulse intervals $(p=0.061)$ and $\sim 64 \%$ increase in pulse duration ( $p=0.089$; Table 3$)$. There were no other differences in quantified LH parameters. Episodic LH release in each PA and control female monkey is illustrated in Figure 1a and b, respectively, showing the extent of individual variation in $\mathrm{LH}$ episodic release observed in each female monkey group. Controls exhibited LH pulse frequencies typical for daytime values during the 
Table 1. Baseline characteristics of adult, ovary intact control and PCOS-like EPA female rhesus monkeys during the early follicular phase of a menstrual cycle or anovulatory period

\begin{tabular}{|c|c|c|c|}
\hline Parameter $($ mean \pm SEM $)$ & Control $(n=3)$ & PCOS-like EPA $(n=4)$ & $p$ value \\
\hline \multicolumn{4}{|l|}{ Age, size, menstrual cycle } \\
\hline Age, years & $24.0 \pm 0.6$ & $24.8 \pm 0.5$ & 0.350 \\
\hline Body weight, kg & $9.1 \pm 0.4$ & $8.8 \pm 1.1$ & 0.750 \\
\hline BMI, $\mathrm{kg} / \mathrm{m}^{2}$ & $42.3 \pm 2.4$ & $38.4 \pm 4.0$ & 0.440 \\
\hline Menstrual cycle, days & $30.6 \pm 3.0$ & $47.0 \pm 11.6$ & 0.296 \\
\hline Intermittent menstrual cycles, $\%(n)$ & $0(0 / 3)$ & $50(2 / 4)$ & 0.429 \\
\hline \multicolumn{4}{|l|}{ Hormones } \\
\hline Testosterone, ng/mL & $0.12 \pm 0.03$ & $0.19 \pm 0.02$ & 0.077 \\
\hline Androstenedione, $\mathrm{ng} / \mathrm{mL}$ & $0.40 \pm 011$ & $0.40 \pm 0.10$ & 0.980 \\
\hline DHEA, ng/mL & $0.11 \pm 0.02$ & $0.17 \pm 0.02$ & 0.107 \\
\hline Total androgens, nmol/L & $2.20 \pm 0.39$ & $2.67 \pm 0.34$ & 0.388 \\
\hline Estradiol, pg/mL & $14.40 \pm 4.55$ & $6.40 \pm 3.94$ & 0.241 \\
\hline Estrone, $\mathrm{pg} / \mathrm{mL}$ & $3.20 \pm 0.40$ & $3.51 \pm 0.34$ & 0.613 \\
\hline Progesterone, ng/mL & $0.15 \pm 0.07$ & $0.07 \pm 0.06$ & 0.282 \\
\hline LH (immunoactive), ng/mL & $1.12 \pm 0.20$ & $0.91 \pm 0.15$ & 0.226 \\
\hline BioLH (bioactive), ng/mL & $0.21 \pm 0.01$ & $0.23 \pm 0.02$ & 0.387 \\
\hline $\mathrm{FSH}, \mathrm{ng} / \mathrm{mL}$ & $2.68 \pm 0.56$ & $2.73 \pm 0.32$ & 0.944 \\
\hline \multicolumn{4}{|l|}{ Hormone ratios } \\
\hline Testosterone:estradiol & $12.54 \pm 8.45$ & $36.84 \pm 7.32$ & 0.069 \\
\hline Androstenedione:testosterone & $3.70 \pm 1.00$ & $2.40 \pm 0.86$ & 0.355 \\
\hline Estrone:estradiol & $0.34 \pm 0.20$ & $0.74 \pm 0.16$ & 0.177 \\
\hline Androstenedione:estrone & $114 \pm 32$ & $115 \pm 28$ & 0.832 \\
\hline LH:FSH & $0.52 \pm 0.13$ & $0.28 \pm 0.02$ & 0.152 \\
\hline BioLH:LH (immunoactive) & $0.17 \pm 0.01$ & $0.32 \pm 0.06$ & 0.033 \\
\hline
\end{tabular}

Bold values indicate significant differences between female groups.

early-to-mid follicular phase of rhesus monkey menstrual cycles.

When all females in Experiment 1 were considered together (Table 4), circulating androstenedione concentrations positively correlated with $\mathrm{LH}$ pulse amplitude ( $r=$ $0.84, p=0.017)$. No other relationships were identified between endocrine or baseline characteristics (Table 4).

\section{Experiment 2: Exogenous GnRH Stimulation of LH Release}

Once the $10 \mathrm{~h}$ frequently sampled IV assessment of episodic LH release was completed, an IV infusion of $2 \mu \mathrm{g} / \mathrm{kg}$ GnRH increased $(p=0.001)$ circulating LH levels in all females. The immediate increase in LH levels during the first $10 \mathrm{~min}$ following $\mathrm{GnRH}$ infusion was $~ 100 \%$ greater $(p=0.034)$ in PA compared to control females (Fig. 2). The continuing daytime $\mathrm{LH}$ elevation in response to GnRH was otherwise comparable in the $2 \mathrm{fe}$ male groups. No relationships were identified between $\mathrm{LH}$ responses to $\mathrm{GnRH}$ and baseline steroid hormone concentrations.

Increased LH Pulse Frequency in PCOSLike Monkeys
Experiment 3: Acute (3-10 h) BioLH Responses to PR Antagonist, Mifepristone

PR blockade by IM injection of mifepristone revealed a relatively positive percentage difference $(p=0.008)$ in daytime bioLH levels compared to baseline (mean of -1 and $0 \mathrm{~h}$ values) in control, but not PA, monkeys (Fig. 3). Mifepristone-induced responses in bioLH levels were expressed as a percentage of each individual female's baseline value prior to mifepristone administration since bioLH levels remained elevated $(p=0.049)$ throughout (baseline: $0.93 \pm 0.21 \mathrm{ng} / \mathrm{mL} ; 10 \mathrm{~h}: 0.68 \pm$ $0.07 \mathrm{ng} / \mathrm{mL}$ ) in PA compared to control (baseline: $0.30 \pm$ $0.08 \mathrm{ng} / \mathrm{mL} ; 10 \mathrm{~h}: 0.42 \pm 0.14 \mathrm{ng} / \mathrm{mL}$ ) monkeys. When circulating bioLH concentrations were considered, the frequency of bioLH concentrations exceeding baseline was higher $(p=0.002)$ in controls than PA monkeys, 83 vs. $25 \%$, respectively.

Taking all females in Experiment 3 together, percentage change in LH tended to negatively correlate $(r=-0.70$, $p=0.083$ ) with baseline T levels. No other relationships were identified. 
Table 2. Correlations between baseline (early-to-mid follicular phase or anovulatory period) circulating concentrations of ovarian hormones and gonadotropins, as well as menstrual cycle duration for both adult female monkey groups combined $(n=7)$

\begin{tabular}{|c|c|c|c|}
\hline Correlations $^{\mathrm{a}}$ & Slope & $r$ value & $p$ value \\
\hline \multicolumn{4}{|l|}{ Baseline testosterone vs. } \\
\hline Androstenedione & -0.28 & 0.24 & 0.609 \\
\hline Estradiol & -0.19 & 0.08 & 0.867 \\
\hline Estrone & 0.27 & 0.52 & 0.232 \\
\hline Progesterone & -0.44 & 0.15 & 0.751 \\
\hline DHEA & 1.04 & 0.99 & 0.001 \\
\hline LH (immunoactive) & -0.45 & 0.44 & 0.317 \\
\hline BioLH & 0.23 & 0.53 & 0.280 \\
\hline Ratio of bioLH:LH (immunoactive) & 0.81 & 0.75 & 0.088 \\
\hline Menstrual cycle duration & -15.69 & 0.12 & 0.798 \\
\hline \multicolumn{4}{|l|}{ Baseline androstenedione vs. } \\
\hline Estradiol & -0.04 & 0.02 & 0.969 \\
\hline Estrone & -0.05 & 0.11 & 0.814 \\
\hline Progesterone & 0.17 & 0.07 & 0.883 \\
\hline DHEA & -0.13 & 0.16 & 0.737 \\
\hline LH (immunoactive) & 0.49 & 0.57 & 0.183 \\
\hline BioLH & -0.05 & 0.10 & 0.859 \\
\hline Ratio of bioLH:LH (immunoactive) & -0.58 & 0.46 & 0.360 \\
\hline Menstrual cycle duration & 8.99 & 0.08 & 0.861 \\
\hline \multicolumn{4}{|l|}{ Baseline estradiol vs. } \\
\hline Estrone & 0.11 & 0.52 & 0.234 \\
\hline Progesterone & 1.06 & 0.88 & 0.008 \\
\hline DHEA & -0.03 & 0.07 & 0.876 \\
\hline LH (immunoactive) & 0.11 & 0.26 & 0.571 \\
\hline BioLH & 0.07 & 0.37 & 0.473 \\
\hline Ratio of bioLH:LH (immunoactive) & -0.16 & 0.34 & 0.510 \\
\hline Menstrual cycle duration & -39.17 & 0.74 & 0.057 \\
\hline \multicolumn{4}{|l|}{ Baseline progesterone vs. } \\
\hline DHEA & -0.06 & 0.16 & 0.736 \\
\hline LH (immunoactive) & 0.19 & 0.57 & 0.181 \\
\hline BioLH & 0.06 & 0.42 & 0.412 \\
\hline Ratio of bioLH:LH (immunoactive) & -0.20 & 0.54 & 0.270 \\
\hline Menstrual cycle duration & -24.32 & 0.55 & 0.198 \\
\hline
\end{tabular}

\section{Discussion}

This study provides the first evidence for PCOS-like increases in daytime episodic release of pituitary $\mathrm{LH}$, and thus probably hypothalamic $\mathrm{GnRH}$, during the early follicular phase or anovulatory period in PCOS-like, PA adult female rhesus monkeys. The more rapid $\mathrm{LH}$ pulse frequency ( 1 LH pulse/h) observed in PA monkeys is comparable to frequencies previously reported for women with PCOS ( $\sim 1 \mathrm{LH}$ pulse/h) [76], as well as long-term ovariectomized adult (monkey: 0.9 LH pulses/h; human: $\sim 1 \mathrm{LH}$ pulse/h) [77-79] and post-menopausal, ovary intact (monkey and human: $\sim 1 \mathrm{LH}$ pulse/h) individuals [68, 80,81 ], all of whom approximate the frequency of episodic $\mathrm{GnRH}$ release from isolated human hypothalamic neurons [82] and fetal monkey tissue explants [83]. Healthy women and adult female rhesus monkeys with regular menstrual cycles exhibit slower episodic LH release rates, but during the early follicular phase, women approximate PCOS-like rapid frequency of LH release [84].

Since frequency, and not amplitude, discriminates PCOS-like LH release in PA monkeys from that in con- 
trols, neuronal circuitry governing hypothalamic GnRH pulse generation is implicated as providing a neural substrate for PCOS-like pathogenic origins during a specific developmental window. Since not all fetal T programming translates from non-primates to primates, including humans $[51,85]$, it was crucial to establish this specific neuroendocrinopathy in a nonhuman primate model. In female rodents and sheep, for example, fetal $\mathrm{T}$ commonly abolishes maturation of ovarian $\mathrm{E}_{2}$-induced $\mathrm{GnRH} / \mathrm{LH}$ surges in adulthood, preventing ovulation [51, 85]. In contrast, adult female monkeys exposed to naturally occurring [36] or experimentally induced $[33,61]$ fetal $\mathrm{T}$ excess retain the ability to demonstrate ovarian $\mathrm{E}_{2}$ induced LH (and likely GnRH) surges and ovulatory menstrual cycles. Women with PCOS [86], and with known exposure to fetal T excess [87], also demonstrate $\mathrm{E}_{2}$-induced LH surges or ovulatory menstrual cycles.

In fetal rhesus monkeys, GnRH neurons initiate their migration from embryonic origins in the nasal epithelium about 32-36 days of gestation and complete their distribution in the hypothalamus by $\sim 60$ days [88], closely emulating $\mathrm{GnRH}$ neuronal embryonic progression in humans at 6-7 weeks of gestation [85], and approximating the gestational ages encompassed by experimentally induced T exposure of PCOS-like monkeys in the present study. Such discrete T exposure programs impaired negative feedback on $\mathrm{LH}$, as manifest by diminished sensitivity to $\mathrm{E}_{2}$ and ovarian hormone negative feedback [33, 51]. Observable aspects of this PCOS-like neuroendocrine defect, such as elevated LH levels, are present in PA female monkeys from late gestation [29]. In addition, persisting relative hyperandrogenism in adult PA monkeys, may further contribute to AR-mediated negative feedback impairment, as reported for women with PCOS [89]. A T-responsive, hypothalamic developmental window may close after mid-gestation, since female monkeys experiencing $\mathrm{T}$ exposure after mid-gestation exhibit normal basal LH levels in adulthood [51]. Such a developmental window may re-open at puberty, when onset of exogenous T exposure in female monkeys accelerates LH pulse frequency [90], but despite continued exposure to T, LH pulse frequency reverts to normal in adulthood [91].

In our aging, but premenopausal, PA monkeys and controls in the present study, neither hyperandrogenism nor LH hypersecretion are reliably exhibited, findings concordant with previous studies of aging, PCOS-like monkeys [55] and in aging, premenopausal women with PCOS $[92,93]$. Trends toward elevated $\mathrm{T}$ levels and $\mathrm{T}$ to $\mathrm{E}_{2}$ ratio, as well as modest elevations in bioLH levels (Ex-
Table 3. Characteristics of LH episodic release during a 10-h frequently sampled intravenous assessment, together with associated parameters in adult, ovary intact control and PCOS-like PA female rhesus monkeys during the early follicular phase of a menstrual cycle or anovulatory period

\begin{tabular}{llll}
\hline Parameter $^{\mathrm{a}}$ (mean \pm SEM) & $\begin{array}{l}\text { Control } \\
(n=3)\end{array}$ & $\begin{array}{l}\text { PCOS-like } \\
\text { PA }(n=4)\end{array}$ & $p$ value \\
\hline LH episodic release & & & \\
LH pulses/h, $n$ & $\mathbf{0 . 5} \pm \mathbf{0 . 2}$ & $\mathbf{1 . 1} \pm \mathbf{0 . 1}$ & $\mathbf{0 . 0 3 7}$ \\
Inter-pulse interval, min & $110 \pm 24$ & $59 \pm 8$ & 0.061 \\
LH pulse amplitude, ng/mL & $0.33 \pm 0.10$ & $0.36 \pm 0.10$ & 0.526 \\
LH pulse duration, min & $18.9 \pm 4.5$ & $31.0 \pm 3.6$ & 0.089 \\
10-h LH mean, ng/mL & $1.12 \pm 0.20$ & $0.92 \pm 0.14$ & 0.447
\end{tabular}

${ }^{a}$ All parameters were log transformed except number of LH pulses. Bold values indicate significant differences between female groups.

Table 4. Correlations with LH episodic release parameters during a 10 - $\mathrm{h}$ frequently sampled intravenous assessment in adult, ovary intact female rhesus monkeys, control and PCOS-like PA groups combined $(n=7)$, during the early follicular phase or anovulatory period

\begin{tabular}{lccc}
\hline Correlations & Slope & $r$ value & $p$ value \\
\hline Baseline testosterone & & & \\
LH pulses/h, $n$ & 6.54 & 0.26 & 0.579 \\
Inter-pulse interval & -51.57 & 0.20 & 0.673 \\
LH pulse amplitude & -0.10 & 0.25 & 0.583 \\
LH pulse duration & 15.65 & 0.24 & 0.603 \\
\hline Baseline androstenedione & & & \\
LH pulses/h, $n$ & -2.65 & 0.12 & 0.790 \\
Inter-pulse interval & 36.76 & 0.17 & 0.719 \\
LH pulse amplitude & $\mathbf{0 . 2 8}$ & $\mathbf{0 . 8 4}$ & $\mathbf{0 . 0 1 7}$ \\
LH pulse duration & 22.61 & 0.42 & 0.353 \\
\hline Baseline estradiol & & & \\
LH pulses/h, $n$ & -5.87 & 0.57 & 0.181 \\
Inter-pulse interval & 70.66 & 0.67 & 0.102 \\
LH pulse amplitude & -0.06 & 0.36 & 0.425 \\
LH pulse duration & -16.97 & 0.65 & 0.116 \\
\hline Baseline progesterone & & & \\
LH pulses/h, $n$ & -4.50 & 0.52 & 0.227 \\
Inter-pulse interval & 47.14 & 0.53 & 0.217 \\
LH pulse amplitude & -0.02 & 0.18 & 0.700 \\
LH pulse duration & -11.14 & 0.51 & 0.242 \\
\hline
\end{tabular}

Bold values indicate significant differences between female groups.

periment 3 throughout) and episodic LH release are, nevertheless, consistent with less prominent PCOS-like reproductive signs and symptoms during aging $[52,93,94]$.

Since GnRH neurons do not express AR, and ARs are implicated in T-driven, PCOS-like gestational program- 


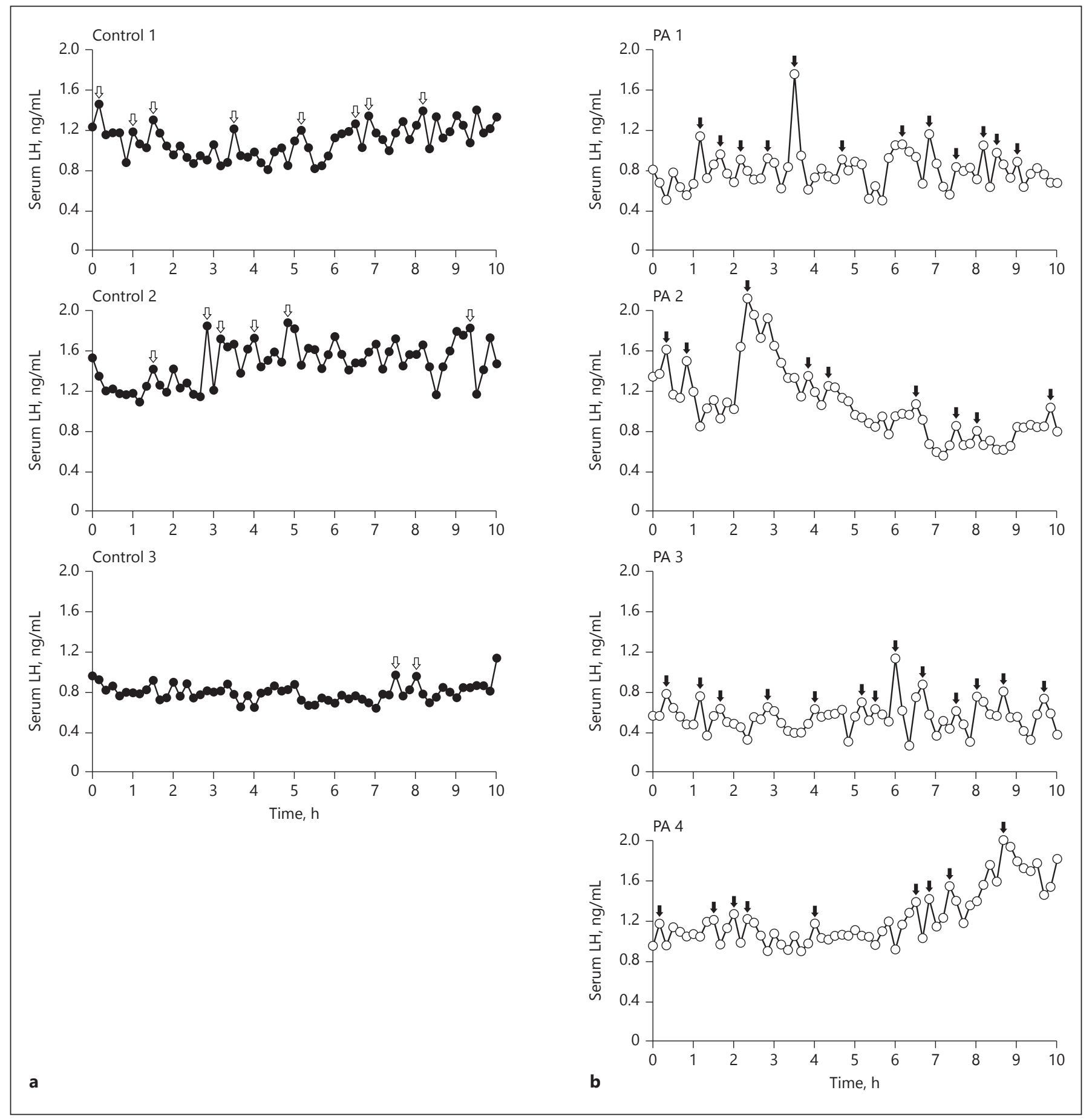

Fig. 1. Serum immunoactive LH levels in (a) 3 adult control (closed symbols), and (b) 4 adult PCOS-like PA (open symbols), female rhesus monkeys during the early follicular phase of the menstrual cycle or period of anovulation, and obtained from 10-min interval blood sampling from an indwelling IV cannula between 08:00 and 16:00 h (daytime). Cannulae were housed within a jacket backpack that attached to a reinforced tether and swivel permitting remote sampling. PULSAR algorithm identified peak episodes of LH release are indicated by arrows: (a) control-1, 8 pulses/10 h; control-2, 6 pulses $/ 10 \mathrm{~h}$; control-3, 2 pulses $/ 10 \mathrm{~h}$, and (b) PA-1, 12 pulses $/ 10 \mathrm{~h}$; PA-2, 9 pulses/10 h: PA-3, 13 pulses/10 h; PA-4, 9 pulses/10 h. PA, prenatally androgenized; $\mathrm{LH}$, luteinizing hormone. 


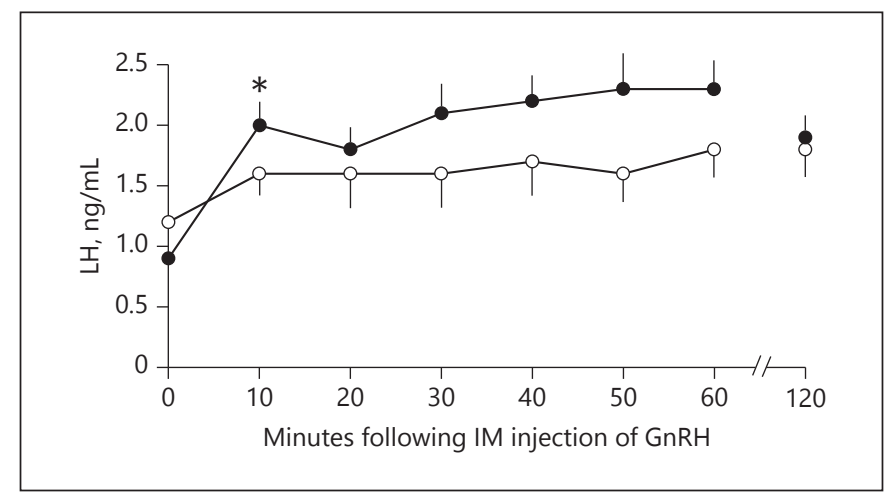

Fig. 2. Serum immunoactive LH responses (mean \pm SEM) to IV infusion of $2 \mu \mathrm{g} / \mathrm{kg} \mathrm{GnRH}$ in adult female control (open symbols) and PA (closed symbols) monkeys immediately following the 10-h assessment of episodic LH release, as described in Figure 1. Only values from 0 to $60 \mathrm{~min}$ and $120 \mathrm{~min}$ following $\mathrm{GnRH}$ infusion are shown. ${ }^{*} p=0.034$ versus $0 \mathrm{~min}$, PA monkeys, alone.

ming [2], including increased LH pulse frequency [47], any pathogenic neural location must lie within the transsynaptic afferent neuronal network to GnRH neurons $[43,95]$. In PA female sheep, fetal $\mathrm{T}$ exposure reduces synaptic input to GnRH neurons [96], including diminished synaptic connections from hypothalamic AR-expressing kisspeptin/neurokinin B/dynorphin (KNDy) neurons [97] and diminished synaptic inter-connections between hypothalamic KNDy neurons accompanying lower post-synaptic expression for the neurokinin B receptor $[97,98]$. Since the kisspeptin and neurokinin B network plays a key role in neuronal stimulation for $\mathrm{GnRH}$ release in rhesus monkeys $[99,100]$ and, together with dynorphin, is functionally implicated in regulating $\mathrm{GnRH}$ release in men [101], fetal T exposure may either enhance kisspeptin and neurokinin B stimulation of episodic GnRH release or impair dynorphin-mediated GnRH inhibition. A KNDy neuronal site for PCOS reproductive pathogenesis is consistent with therapeutic results obtained from neurokinin B NK3-receptor antagonist treatment of women with PCOS. In a recent clinical trial [102], the NK3 receptor antagonist AZD4901 resulted in diminished basal LH, LH pulse frequency, and basal $\mathrm{T}$, and there was an 18 vs. $6 \%$ incidence of ovulation in the placebo group. Thus, novel therapeutic targeting of PCOS neuroendocrine reproductive pathophysiology has the potential to ameliorate PCOS reproductive and endocrine dysfunction. The comparable efficacy of NK3 receptor antagonist, ESN364, in diminishing the frequency of episodic LH release in ovariectomized ewes, $\mathrm{LH}$ levels in castrated male monkeys, and pre-ovulatory LH

Increased LH Pulse Frequency in PCOSLike Monkeys

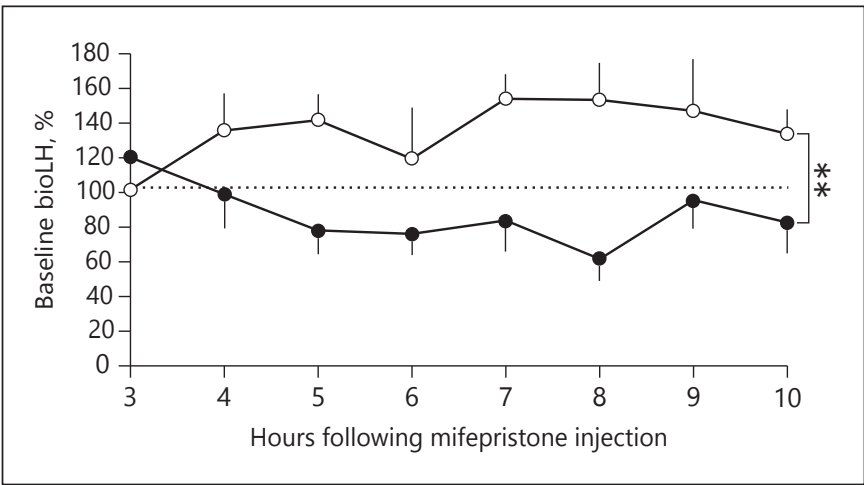

Fig. 3. Percentage change in serum bioLH levels (mean \pm SEM) from baseline (mean of -1 and $0 \mathrm{~h}$ values $=100 \%$ and dashed line) in response to IM injection of $5 \mathrm{mg} / \mathrm{kg}$ mifepristone in adult female control (open symbols) and PA (closed symbols) monkeys between 06:00 and 18:00 h (daytime). ${ }^{* *} p=0.008$, control versus PA monkeys, overall.

surges in female monkeys, reinforces such therapeutic potential [103].

Fetal T exposure has also been shown to alter hypothalamic pre-synaptic glutamate and GABA neuronal inputs to GnRH in both PA female mice [104] and sheep [96]. Increased GABA synaptic connections [43] may enable increased $\mathrm{GABA}_{\mathrm{A}}$ receptor-mediated drive to $\mathrm{GnRH}$ neurons in PA mice [42] likely mediated through depolarization of GnRH neurons $[105,106]$ increasing GnRH release frequency. Such an additional putative neuronal site for PCOS reproductive pathogenesis would complement contributions from KNDy neurons, and would be consistent with a higher incidence of PCOS in GABAenabled psychiatric disorders, such as epilepsy and bipolar disorder [107]. PCOS incidence is further exaggerated by valproate, an anticonvulsant and GABAergic therapeutic, especially among young ( $<26$ years) women [108]. Perhaps most interestingly, hypergonadotropic ovarian hyperandrogenism was recently induced in a mouse model for PCOS by the systemic administration of anti-Mullerian hormone (AMH), likely resulting in increased hypothalamic GABAergic synaptic connections to GnRH neurons driving hyperactive GnRH release [109]. While it is not known whether PA monkeys have altered hypothalamic pre-synaptic glutamate and GABA neuronal inputs to $\mathrm{GnRH}$, or whether they release $\mathrm{GnRH}$ in response to $\mathrm{AMH}$, as demonstrated in female mice [110], they do not exhibit elevated AMH levels in their late reproductive years [55], making ovarian $\mathrm{AMH}$ an unlikely contributor to the present nonhuman primate findings. 
A single injection of the selective PR antagonist mifepristone, on the other hand, modestly differentiated LH responses in the 2 female monkey groups, suggestive of blunted, PCOS-like diminished progesterone negative feedback on daytime LH levels [111] in PA monkeys. Interestingly, there was a trend for circulating levels of T to negatively correlate with percentage $\mathrm{LH}$ response to mifepristone in all female monkeys combined, potentially implicating prevailing hyperandrogenism in disrupting progesterone-regulated negative feedback on $\mathrm{GnRH} / \mathrm{LH}$ release. While LH responses to PR blockade have not been reported for women with PCOS, administering luteal phase levels of exogenous progesterone to PCOS women fails to diminish their rapid $\mathrm{LH}$ release frequencies in contrast to the same hormone's clear efficacy in suppressing LH release episodes in healthy women with regular menstrual cycles [4]. In addition, mifepristone is inconsistent in elevating LH levels when administered to healthy women during the early follicular phase [112-114] and fails to reverse exogenous $\mathrm{E}_{2}$ and progesterone-induced slowing of $\mathrm{GnRH}$ pulse frequency in healthy women when it replaces 10 days of prior exogenous progesterone therapy [69]. Such unexpectedly mixed effects of mifepristone may stem from its suppression of $\mathrm{Ca}^{++}$-mediated membrane depolarization [115] crucial for exocytosis of GnRH and LH, and from its antagonism at the glucocorticoid receptor [116], potentially inducing compensatory elevation in hypothalamic $\mathrm{CRH}$, and potentially, GnRH suppression [117].

Endogenous $\mathrm{E}_{2}$ levels in our study subjects are relatively low for adult female rhesus monkeys [34, 118], possibly reflecting our employment of a more specific and sensitive LC-MS/MS assay method that generates considerably lower circulating values than immunoassays [29, 75], in addition to previously reported and continuing impairments in ovarian folliculogenesis and luteal sufficiency in PA subjects $[58,118]$. Comparable ovarian defects also manifest in women with PCOS [119]. While such characteristics might be considered as signs of approaching menopause ( 25-27 years of age in rhesus monkeys) $[120,121]$, monkeys in both study groups demonstrate comparable $\mathrm{LH}$ and FSH levels to those previously reported at younger ages ( 21-23 years of age) [55] and typically found in premenopausal adult female rhesus monkeys undergoing regular or intermittent ovulatory menstrual cycles [121]. Additionally, no monkeys in this study were amenorrheic.

With regard to strengths of this study, we employed the most comprehensive animal model for PCOS, PA female rhesus monkeys exposed to gestational $\mathrm{T}$ excess during early-to-mid gestation, and used previously val- idated quantitative assessment of LH episodic release in adult female rhesus monkeys, together with a highly specific and sensitive LC-MS/MS assay method. Limitations include small numbers of monkeys per treatment group, in compliance with contemporary refinement and reduction practices for laboratory nonhuman primates; the use of systemic circulation concentrations of $\mathrm{LH}$ as a secondary measure for hypothalamic GnRH release; and the use of adult female rhesus macaques in their late reproductive, pre-menopausal years, thus PA monkeys in this study, typical of comparable aged women with PCOS [93], exhibited less pronounced hyperandrogenism and hypergonadotropism, and combined ovulatory with oligo-ovulatory females, as occurs when PCOS is diagnosed using Rotterdam 2003 criteria [8].

In summary, these results suggest a neural pathogenic site for PCOS-like reproductive endocrinopathy in a nonhuman primate model, distinguished from its non-primate counterparts by singular disruption of negative, but not positive, feedback regulation. This opens the door to novel and site-specific, central nervous system therapeutic targeting of PCOS neuroendocrine reproductive pathophysiology with the potential to ameliorate infertility, hyperandrogenemia, and their sequelae.

\section{Acknowledgments}

We thank Drs. Deborah Barnett, Cristin Bruns, Rao Zhou, and Jason Lang, as well as Jim Turk, for technical assistance, together with Animal, Veterinary and Assays Services of the WNPRC for excellent service support; and Drs. Matthew Flowers and Marissa Kraynak for commenting on earlier drafts of this manuscript. This work was funded in part by NIH grants P50 HD044405 (PI: Dunaif), P50 HD028934 (PI: Marshall), and R01 RR013635 (PI: Abbott).

\section{References}

1 Wild RA, Carmina E, Diamanti-Kandarakis E, Dokras A, Escobar-Morreale HF, Futterweit W, Lobo R, Norman RJ, Talbott E, Dumesic DA: Assessment of cardiovascular risk and prevention of cardiovascular disease in women with the polycystic ovary syndrome: a consensus statement by the Androgen Excess and Polycystic Ovary Syndrome (AE-PCOS) Society. J Clin Endocrinol Metab 2010;95:2038-2049.

2 Caldwell AS, Eid S, Kay CR, Jimenez M, McMahon AC, Desai R, Allan CM, Smith JT, Handelsman DJ, Walters KA: Haplosufficient genomic androgen receptor signaling is adequate to protect female mice from induction of polycystic ovary syndrome features by prenatal hyperandrogenization. Endocrinology 2015;156:1441-1452. 
3 Caldwell ASL, Edwards MC, Desai R, Jimenez M, Gilchrist RB, Handelsman DJ, Walters KA: Neuroendocrine androgen action is a key extraovarian mediator in the development of polycystic ovary syndrome. Proc Natl Acad Sci USA 2017;114:E3334-E3343.

4 Pastor CL, Griffin-Korf ML, Aloi JA, Evans WS, Marshall JC: Polycystic ovary syndrome: evidence for reduced sensitivity of the gonadotropin-releasing hormone pulse generator to inhibition by estradiol and progesterone. J Clin Endocrinol Metab 1998;83:582-590.

5 Burt Solorzano CM, Beller JP, Abshire MY, Collins JS, McCartney CR, Marshall JC: Neuroendocrine dysfunction in polycystic ovary syndrome. Steroids 2012;77:332-337.

6 Hayes MG, Urbanek M, Ehrmann DA, Armstrong LL, Lee JY, Sisk R, Karaderi T, Barber TM, McCarthy MI, Franks S, Lindgren CM, Welt CK, Diamanti-Kandarakis E, Panidis D, Goodarzi MO, Azziz R, Zhang Y, James RG, Olivier M, Kissebah AH; Reproductive Medicine Network, Stener-Victorin E, Legro RS, Dunaif A: Genome-wide association of polycystic ovary syndrome implicates alterations in gonadotropin secretion in European ancestry populations. Nat Commun 2015;6:7502.

7 Jones MR, Brower MA, Xu N, Cui J, Mengesha E, Chen YD, Taylor KD, Azziz R, Goodarzi MO: Systems genetics reveals the functional context of PCOS loci and identifies genetic and molecular mechanisms of disease heterogeneity. PLoS Genet 2015;11:e1005455.

8 Dumesic DA, Oberfield SE, Stener-Victorin E, Marshall JC, Laven JS, Legro RS: Scientific statement on the diagnostic criteria, epidemiology, pathophysiology, and molecular genetics of polycystic ovary syndrome. Endocr Rev 2015;36:487-525.

9 Christman GM, Randolph JF, Kelch RP, Marshall JC: Reduction of gonadotropin-releasing hormone pulse frequency is associated with subsequent selective follicle-stimulating hormone secretion in women with polycystic ovarian disease. J Clin Endocrinol Metab 1991;72:1278-1285.

10 Marshall JC, Griffin ML: The role of changing pulse frequency in the regulation of ovulation. Hum Reprod 1993;8(suppl 2): 57-61.

11 Diamanti-Kandarakis E, Dunaif A: Insulin resistance and the polycystic ovary syndrome revisited: an update on mechanisms and implications. Endocr Rev 2012;33:981-1030.

12 Franks S, Stark J, Hardy K: Follicle dynamics and anovulation in polycystic ovary syndrome. Hum Reprod Update 2008;14:367-378.

13 Laird M, Thomson K, Fenwick M, Mora J, Franks S, Hardy K: Androgen stimulates growth of mouse preantral follicles in vitro: interaction with follicle-stimulating hormone and with growth factors of the TGF $\beta$ superfamily. Endocrinology 2017; 158:920935 .

14 Dunaif A: Perspectives in polycystic ovary syndrome: from hair to eternity. J Clin Endocrinol Metab 2016;101:759-768.
15 Daniels TL, Berga SL: Resistance of gonadotropin releasing hormone drive to sex steroid-induced suppression in hyperandrogenic anovulation. J Clin Endocrinol Metab 1997;82:4179-4183.

16 Zumoff B, Freeman R, Coupey S, Saenger P, Markowitz M, Kream J: A chronobiologic abnormality in luteinizing hormone secretion in teenage girls with the polycystic-ovary syndrome. N Engl J Med 1983;309:1206-1209.

17 Apter D, Vihko R: Endocrine determinants of fertility: serum androgen concentrations during follow-up of adolescents into the third decade of life. J Clin Endocrinol Metab 1990; 71:970-974.

18 Venturoli S, Porcu E, Fabbri R, Magrini O, Gammi L, Paradisi R, Flamigni C: Longitudinal evaluation of the different gonadotropin pulsatile patterns in anovulatory cycles of young girls. J Clin Endocrinol Metab 1992; 74:836-841.

19 Apter D, Bützow T, Laughlin GA, Yen SS: Accelerated 24-h luteinizing hormone pulsatile activity in adolescent girls with ovarian hyperandrogenism: relevance to the developmental phase of polycystic ovarian syndrome. J Clin Endocrinol Metab 1994; 79:119-125.

20 Collins JS, Beller JP, Burt Solorzano C, Patrie JT, Chang RJ, Marshall JC, McCartney CR: Blunted day-night changes in luteinizing hormone pulse frequency in girls with obesity: the potential role of hyperandrogenemia. J Clin Endocrinol Metab 2014;99:2887-2896.

21 Chhabra S, McCartney CR, Yoo RY, Eagleson CA, Chang RJ, Marshall JC: Progesterone inhibition of the hypothalamic gonadotropinreleasing hormone pulse generator: evidence for varied effects in hyperandrogenemic adolescent girls. J Clin Endocrinol Metab 2005; 90:28102815.

22 Hakim C, Padmanabhan V, Vyas AK: Gestational Hyperandrogenism in Developmental Programming. Endocrinology 2017;158:199212.

23 Walters KA: Androgens in polycystic ovary syndrome: lessons from experimental models. Curr Opin Endocrinol Diabetes Obes 2016:23:257-263

24 Abbott DH, Levine JE, Dumesic DA: Translational Insight Into Polycystic Ovary Syndrome (PCOS) From Female Monkeys with PCOSlike Traits. Curr Pharm Des 2016;22:56255633.

25 Daan NM, Koster MP, Steegers-Theunissen RP, Eijkemans MJ, Fauser BC: Endocrine and cardiometabolic cord blood characteristics of offspring born to mothers with and without polycystic ovary syndrome. Fertil Steril 2017; 107:261-268.e3.

$26 \mathrm{Wu}$ Y, Zhong G, Chen S, Zheng C, Liao D, Xie M: Polycystic ovary syndrome is associated with anogenital distance, a marker of prenatal androgen exposure. Hum Reprod 2017;32:937-943.

27 Homburg R, Gudi A, Shah A, M Layton A: A novel method to demonstrate that pregnant women with polycystic ovary syndrome hyper-expose their fetus to androgens as a possible stepping stone for the developmental theory of PCOS. A pilot study. Reprod Biol Endocrinol 2017;15:61.

28 Barrett ES, Hoeger KM, Sathyanarayana S, Abbott DH, Redmon JB, Nguyen RHN, Swan $\mathrm{SH}$ : Anogenital distance in newborn daughters of women with polycystic ovary syndrome indicates fetal testosterone exposure. J Dev Orig Health Dis 2018;9:1-8.

29 Abbott DH, Barnett DK, Levine JE, Padmanabhan V, Dumesic DA, Jacoris S, Tarantal AF: Endocrine antecedents of polycystic ovary syndrome in fetal and infant prenatally androgenized female rhesus monkeys. Biol Reprod 2008;79:154-163.

30 Abbott DH, Dumesic DA, Eisner JR, Colman RJ, Kemnitz JW: Insights into the development of polycystic ovary syndrome (PCOS) from studies of prenatally androgenized female rhesus monkeys. Trends Endocrinol Metab 1998;9:62-67.

31 Abbott DH, Tarantal AF, Dumesic DA: Fetal, infant, adolescent and adult phenotypes of polycystic ovary syndrome in prenatally androgenized female rhesus monkeys. Am J Primatol 2009;71:776-784.

32 Keller E, Chazenbalk GD, Aguilera P, Madrigal V, Grogan T, Elashoff D, Dumesic DA, Abbott DH: Impaired preadipocyte differentiation into adipocytes in subcutaneous abdominal adipose of PCOS-like female rhesus monkeys. Endocrinology 2014;155:2696-2703.

33 Steiner RA, Clifton DK, Spies HG, Resko JA: Sexual differentiation and feedback control of luteinizing hormone secretion in the rhesus monkey. Biol Reprod 1976;15:206-212.

34 Dumesic DA, Schramm RD, Peterson E, Paprocki AM, Zhou R, Abbott DH: Impaired developmental competence of oocytes in adult prenatally androgenized female rhesus monkeys undergoing gonadotropin stimulation for in vitro fertilization. J Clin Endocrinol Metab 2002;87:1111-1119.

35 Arifin E, Shively CA, Register TC, Cline JM: Polycystic ovary syndrome with endometrial hyperplasia in a cynomolgus monkey (Macaca fascicularis). Vet Pathol 2008;45:512-515.

36 Abbott DH, Rayome BH, Dumesic DA, Lewis KC, Edwards AK, Wallen K, Wilson ME, Appt SE, Levine JE: Clustering of PCOS-like traits in naturally hyperandrogenic female rhesus monkeys. Hum Reprod 2017;32:923-936.

37 Robinson JE, Forsdike RA, Taylor JA: In utero exposure of female lambs to testosterone reduces the sensitivity of the gonadotropin-releasing hormone neuronal network to inhibition by progesterone. Endocrinology 1999; 140:5797-5805.

38 Savabieasfahani M, Lee JS, Herkimer C, Sharma TP, Foster DL, Padmanabhan V: Fetal programming: testosterone exposure of the female sheep during midgestation disrupts the dynamics of its adult gonadotropin secretion during the periovulatory period. Biol Reprod 2005;72:221-229. 
39 Steckler TL, Herkimer C, Dumesic DA, Padmanabhan V: Developmental programming: excess weight gain amplifies the effects of prenatal testosterone excess on reproductive cyclicity - implication for polycystic ovary syndrome. Endocrinology 2009;150:1456-1465.

40 Foecking EM, McDevitt MA, Acosta-Martínez M, Horton TH, Levine JE: Neuroendocrine consequences of androgen excess in female rodents. Horm Behav 2008;53:673-692.

41 Yan X, Yuan C, Zhao N, Cui Y, Liu J: Prenatal androgen excess enhances stimulation of the GNRH pulse in pubertal female rats. J Endocrinol 2014;222:73-85.

42 Sullivan SD, Moenter SM: Prenatal androgens alter GABAergic drive to gonadotropin-releasing hormone neurons: implications for a common fertility disorder. Proc Natl Acad Sci USA 2004;101:7129-7134.

43 Moore AM, Prescott M, Marshall CJ, Yip SH, Campbell RE: Enhancement of a robust arcuate GABAergic input to gonadotropin-releasing hormone neurons in a model of polycystic ovarian syndrome. Proc Natl Acad Sci USA 2015;112:596-601.

44 Sarma HN, Manikkam M, Herkimer C, Dell'Orco J, Welch KB, Foster DL, Padmanabhan V: Fetal programming: excess prenatal testosterone reduces postnatal luteinizing hormone, but not follicle-stimulating hormone responsiveness, to estradiol negative feedback in the female. Endocrinology 2005; 146:4281-4291.

45 Veiga-Lopez A, Ye W, Phillips DJ, Herkimer C, Knight PG, Padmanabhan V: Developmental programming: deficits in reproductive hormone dynamics and ovulatory outcomes in prenatal, testosterone-treated sheep. Biol Reprod 2008;78:636-647.

46 Roland AV, Moenter SM: Reproductive neuroendocrine dysfunction in polycystic ovary syndrome: insight from animal models. Front Neuroendocrinol 2014;35:494-511.

47 Moore AM, Campbell RE: Polycystic ovary syndrome: Understanding the role of the brain. Front Neuroendocrinol 2017;46: $1-14$.

48 Plant TM: A comparison of the neuroendocrine mechanisms underlying the initiation of the preovulatory LH surge in the human, Old World monkey and rodent. Front Neuroendocrinol 2012;33:160-168.

49 Norman RL, Spies HG: Cyclic ovarian function in a male macaque: additional evidence for a lack of sexual differentiation in the physiological mechanisms that regulate the cyclic release of gonadotropins in primates. Endocrinology 1986;118:2608-2610.

50 Terasawa E, Garcia JP, Seminara SB, Keen KL: Role of kisspeptin and neurokinin B in puberty in female non-human primates. Front Endocrinol 2018;9:148.

51 Abbott DH, Barnett DK, Bruns CM, Dumesic DA: Androgen excess fetal programming of female reproduction: a developmental aetiology for polycystic ovary syndrome? Hum Reprod Update 2005;11:357-374.
52 Abbott DH: Neuronal androgen receptor: Molecular gateway to polycystic ovary syndrome? Proc Natl Acad Sci USA 2017;114: 4045-4047.

53 Levine JE, Norman RL, Gliessman PM, Oyama TT, Bangsberg DR, Spies HG: In vivo gonadotropin-releasing hormone release and serum luteinizing hormone measurements in ovariectomized, estrogen-treated rhesus macaques. Endocrinology 1985;117:711-721.

54 Gearing M, Terasawa E: Luteinizing hormone releasing hormone (LHRH) neuroterminals mapped using the push-pull perfusion method in the rhesus monkey. Brain Res Bull 1988; 21:117-121.

55 Dumesic DA, Patankar MS, Barnett DK, Lesnick TG, Hutcherson BA, Abbott DH: Early prenatal androgenization results in diminished ovarian reserve in adult female rhesus monkeys. Hum Reprod 2009;24:3188-3195.

56 Bruns CM, Baum ST, Colman RJ, Dumesic DA, Eisner JR, Jensen MD, Whigham LD, Abbott DH: Prenatal androgen excess negatively impacts body fat distribution in a nonhuman primate model of polycystic ovary syndrome. Int J Obes (Lond) 2007;31:1579-1585.

57 Colman RJ, Kemnitz JW, Lane MA, Abbott $\mathrm{DH}$, Binkley N: Skeletal effects of aging and menopausal status in female rhesus macaques. J Clin Endocrinol Metab 1999;84: 4144-4148.

58 Zhou R, Bruns CM, Bird IM, Kemnitz JW, Goodfriend TL, Dumesic DA, Abbott DH: Pioglitazone improves insulin action and normalizes menstrual cycles in a majority of prenatally androgenized female rhesus monkeys. Reprod Toxicol 2007;23:438-448.

59 Abbott AD, Colman RJ, Tiefenthaler R, Dumesic DA, Abbott DH: Early-to-mid gestation fetal testosterone increases right hand 2D:4D finger length ratio in polycystic ovary syndromelike monkeys. PLoS One 2012;7:e42372.

60 Abbott DH, Dumesic DA, Franks S: Developmental origin of polycystic ovary syndrome - a hypothesis. J Endocrinol 2002;174:1-5.

61 Dumesic DA, Abbott DH, Eisner JR, Goy RW Prenatal exposure of female rhesus monkeys to testosterone propionate increases serum luteinizing hormone levels in adulthood. Fertil Steril 1997;67:155-163.

62 Eisner JR, Barnett MA, Dumesic DA, Abbott $\mathrm{DH}$ : Ovarian hyperandrogenism in adult female rhesus monkeys exposed to prenatal androgen excess. Fertil Steril 2002;77:167-172.

63 Eisner JR, Dumesic DA, Kemnitz JW, Abbott DH: Timing of prenatal androgen excess determines differential impairment in insulin secretion and action in adult female rhesus monkeys. J Clin Endocrinol Metab 2000;85:1206-1210.

64 McCartney CR, Blank SK, Marshall JC: Progesterone acutely increases LH pulse amplitude but does not acutely influence nocturnal LH pulse frequency slowing during the late follicular phase in women. Am J Physiol Endocrinol Metab 2007;292:E900E906.
65 Terasawa E, Krook C, Eman S, Watanabe G, Bridson WE, Sholl SA, Hei DL: Pulsatile luteinizing hormone $(\mathrm{LH})$ release during the progesterone-induced LH surge in the female rhesus monkey. Endocrinology 1987;120:22652271.

66 Gearing M, Terasawa E: Suppression of luteinizing hormone release by the alpha- 1 adrenergic receptor antagonist prazosin in the ovariectomized female rhesus monkey. Am J Primatol 1991;25:23-33.

67 Merriam GR, Wachter KW: Algorithms for the study of episodic hormone secretion. Am J Physiol 1982;243:E310-E318.

68 Woller MJ, Everson-Binotto G, Nichols E, Acheson A, Keen KL, Bowers CY, Terasawa E: Aging-related changes in release of growth hormone and luteinizing hormone in female rhesus monkeys. J Clin Endocrinol Metab 2002;87:5160-5167.

69 McCartney CR, Blank SK, Marshall JC: Estradiol and progesterone-induced slowing of gonadotropin-releasing hormone pulse frequency is not reversed by subsequent administration of mifepristone. Endocrine 2009;36: 239-245.

70 Heikinheimo O, Kekkonen R, Lähteenmäki P: The pharmacokinetics of mifepristone in humans reveal insights into differential mechanisms of antiprogestin action. Contraception 2003;68:421-426.

71 Bauer-Dantoin AC, Tabesh B, Norgle JR, Levine JE: RU486 administration blocks neuropeptide $\mathrm{Y}$ potentiation of luteinizing hormone (LH)-releasing hormone-induced $\mathrm{LH}$ surges in proestrous rats. Endocrinology 1993;133:2418-2423.

72 Sarkar NN: Mifepristone: bioavailability, pharmacokinetics and use-effectiveness. Eur J Obstet Gynecol Reprod Biol 2002;101:113120.

73 Foong SC, Abbott DH, Zschunke MA, Lesnick TG, Phy JL, Dumesic DA: Follicle luteinization in hyperandrogenic follicles of polycystic ovary syndrome patients undergoing gonadotropin therapy for in vitro fertilization. J Clin Endocrinol Metab 2006;91:23272333.

74 Kraynak M, Flowers MT, Shapiro RA, Kapoor A, Levine JE, Abbott DH: Extra-ovarian gonadotropin negative feedback revealed by aromatase inhibition in female marmoset monkeys. Am J Physiol Endocrinol Metab 2017;313:E507-E514.

75 Sokal RR, Rohlf FJ: Biometry, ed 4. New York, WH Freeman and Co., 2012.

76 Waldstreicher J, Santoro NF, Hall JE, Filicori M, Crowley WF Jr: Hyperfunction of the hypothalamic-pituitary axis in women with polycystic ovarian disease: indirect evidence for partial gonadotroph desensitization. J Clin Endocrinol Metab 1988;66:165-172.

77 Dubey AK, Plant TM: Testosterone administration to ovariectomized female rhesus monkeys (Macaca mulatta) reduces the frequency of pulsatile luteinizing hormone secretion. Biol Reprod 1985;32:1109-1115. 
78 Vulliémoz NR, Xiao E, Xia-Zhang L, Rivier J, Ferin M: Astressin B, a nonselective corticotropin-releasing hormone receptor antagonist, prevents the inhibitory effect of ghrelin on luteinizing hormone pulse frequency in the ovariectomized rhesus monkey. Endocrinology 2008;149:869-874.

79 Graña-Barcia M, Lado-Abeal J, Liz-Lestón JL, Lojo S, Novo-Domínguez A, Aguilar-Fernández J: Depression of FSH and LH secretion following pulsatile GnRH administration in ovariectomized women. Hum Reprod 1998; 13:525-530.

80 Keenan DM, Evans WS, Veldhuis JD: Control of LH secretory-burst frequency and interpulse-interval regularity in women. Am J Physiol Endocrinol Metab 2003;285:E938-E948.

81 Lavoie HB, Marsh EE, Hall JE: Absence of apparent circadian rhythms of gonadotropins and free alpha-subunit in postmenopausal women: evidence for distinct regulation relative to other hormonal rhythms. J Biol Rhythms 2006;21:58-67.

82 Rasmussen DD, Gambacciani M, Swartz W, Tueros VS, Yen SS: Pulsatile gonadotropinreleasing hormone release from the human mediobasal hypothalamus in vitro: opiate receptor-mediated suppression. Neuroendocrinology 1989;49:150-156.

83 Terasawa E, Keen KL, Mogi K, Claude P: Pulsatile release of luteinizing hormone-releasing hormone (LHRH) in cultured LHRH neurons derived from the embryonic olfactory placode of the rhesus monkey. Endocrinology 1999;140:1432-1441.

84 Blank SK, McCartney CR, Helm KD, Marshall JC: Neuroendocrine effects of androgens in adult polycystic ovary syndrome and female puberty. Semin Reprod Med 2007;25: 352-359.

85 Schwanzel-Fukuda M, Crossin KL, Pfaff DW, Bouloux PM, Hardelin JP, Petit C: Migration of luteinizing hormone-releasing hormone (LHRH) neurons in early human embryos. J Comp Neurol 1996;366:547-557.

86 Baird DT, Corker CS, Davidson DW, Hunter WM, Michie EA, Van Look PF: Pituitary-ovarian relationships in polycystic ovary syndrome. J Clin Endocrinol Metab 1977;45:798-801.

87 Claahsen-van der Grinten HL, Stikkelbroeck NM, Sweep CG, Hermus AR, Otten BJ: Fertility in patients with congenital adrenal hyperplasia. J Pediatr Endocrinol Metab 2006;19: 677-685.

88 Terasawa E, Quanbeck CD, Schulz CA, Burich AJ, Luchansky LL, Claude P: A primary cell culture system of luteinizing hormone releasing hormone neurons derived from embryonic olfactory placode in the rhesus monkey. Endocrinology 1993;133:2379-2390.

89 Eagleson CA, Gingrich MB, Pastor CL, Arora TK, Burt CM, Evans WS, Marshall JC: Polycystic ovarian syndrome: evidence that flutamide restores sensitivity of the gonadotropin-releasing hormone pulse generator to inhibition by estradiol and progesterone. J Clin Endocrinol Metab 2000;85:4047-4052.
90 McGee WK, Bishop CV, Bahar A, Pohl CR, Chang RJ, Marshall JC, Pau FK, Stouffer RL, Cameron JL: Elevated androgens during puberty in female rhesus monkeys lead to increased neuronal drive to the reproductive axis: a possible component of polycystic ovary syndrome. Hum Reprod 2012;27:531540.

91 McGee WK, Bishop CV, Pohl CR, Chang RJ, Marshall JC, Pau FK, Stouffer RL, Cameron JL: Effects of hyperandrogenemia and increased adiposity on reproductive and metabolic parameters in young adult female monkeys. Am J Physiol Endocrinol Metab 2014;306:E1292-E1304.

92 Welt CK, Carmina E: Clinical review: Lifecycle of polycystic ovary syndrome (PCOS): from in utero to menopause. J Clin Endocrinol Metab 2013;98:4629-4638.

93 Carmina E, Campagna AM, Lobo RA: A 20year follow-up of young women with polycystic ovary syndrome. Obstet Gynecol 2012;119:263-269.

94 Huddleston HG, Quinn MM, Kao CN, Lenhart N, Rosen MP, Cedars MI: Women with polycystic ovary syndrome demonstrate worsening markers of cardiovascular risk over the short-term despite declining hyperandrogenaemia: results of a longitudinal study with community controls. Clin Endocrinol (Oxf) 2017;87:775-782.

95 Huang X, Harlan RE: Absence of androgen receptors in LHRH immunoreactive neurons. Brain Res 1993;624:309-311.

96 Jansen HT, Hershey J, Mytinger A, Foster DL, Padmanabhan V: Developmental programming: reproductive endocrinopathies in the adult female sheep after prenatal testosterone treatment are reflected in altered ontogeny of GnRH afferents. Endocrinology 2011;152:4288-4297.

97 Cernea M, Padmanabhan V, Goodman RL, Coolen LM, Lehman MN: Prenatal Testosterone Treatment Leads to Changes in the Morphology of KNDy Neurons, Their Inputs, and Projections to GnRH Cells in Female Sheep. Endocrinology 2015;156:32773291.

98 Ahn T, Fergani C, Coolen LM, Padmanabhan V, Lehman MN: Prenatal testosterone excess decreases neurokinin 3 receptor immunoreactivity within the arcuate nucleus KNDy cell population. J Neuroendocrinol 2015;27:100-110.

99 Garcia JP, Guerriero KA, Keen KL, Kenealy BP, Seminara SB, Terasawa E: Kisspeptin and neurokinin $\mathrm{B}$ signaling network underlies the pubertal increase in GnRH release in female rhesus monkeys. Endocrinology 2017;158:3269-3280.

100 Kurian JR, Keen KL, Guerriero KA, Terasawa $\mathrm{E}$ : Tonic control of kisspeptin release in prepubertal monkeys: implications to the mechanism of puberty onset. Endocrinology 2012;153:3331-3336.

101 Narayanaswamy S, Prague JK, Jayasena CN, Papadopoulou DA, Mizamtsidi M, Shah AJ,
Bassett P, Comninos AN, Abbara A, Bloom SR, Veldhuis JD, Dhillo WS: Investigating the KNDy hypothesis in humans by coadministration of kisspeptin, neurokinin B, and naltrexone in men. J Clin Endocrinol Metab 2016;101:3429-3436.

102 George JT, Kakkar R, Marshall J, Scott ML, Finkelman RD, Ho TW, Veldhuis J, Skorupskaite K, Anderson RA, McIntosh S, Webber L: Neurokinin B receptor antagonism in women with polycystic ovary syndrome: a randomized, placebo-controlled trial. J Clin Endocrinol Metab 2016;101: 4313-4321.

103 Fraser GL, Hoveyda HR, Clarke IJ, Ramaswamy S, Plant TM, Rose C, Millar RP: The NK3 receptor antagonist ESN364 interrupts pulsatile LH secretion and moderates levels of ovarian hormones throughout the menstrual cycle. Endocrinology 2015;156:42144225.

104 Penatti CA, Oberlander JG, Davis MC, Porter DM, Henderson LP: Chronic exposure to anabolic androgenic steroids alters activity and synaptic function in neuroendocrine control regions of the female mouse. Neuropharmacology 2011;61:653-664.

105 DeFazio RA, Heger S, Ojeda SR, Moenter SM: Activation of A-type gamma-aminobutyric acid receptors excites gonadotropinreleasing hormone neurons. Mol Endocrinol 2002;16:2872-2891.

106 Herbison AE, Moenter SM: Depolarising and hyperpolarising actions of GABA(A) receptor activation on gonadotrophin-releasing hormone neurones: towards an emerging consensus. J Neuroendocrinol 2011;23 557-569.

107 Reynolds MF, Sisk EC, Rasgon NL: Valproate and neuroendocrine changes in relation to women treated for epilepsy and bipolar disorder: a review. Curr Med Chem 2007;14: 2799-2812.

108 Morrell MJ, Hayes FJ, Sluss PM, Adams JM, Bhatt M, Ozkara C, Warnock CR, Isojärvi J: Hyperandrogenism, ovulatory dysfunction, and polycystic ovary syndrome with valproate versus lamotrigine. Ann Neurol 2008;64:200211.

109 Giacobini P: AMH, GnRH and PCOS: What are the interactions? Endocr Rev 2017; 38(suppl):S38.

110 Cimino I, Casoni F, Liu X, Messina A, Parkash J, Jamin SP, Catteau-Jonard S, Collier F, Baroncini M, Dewailly D, Pigny P, Prescott M, Campbell R, Herbison AE, Prevot V, Giacobini P: Novel role for anti-Müllerian hormone regulation of $\mathrm{GnRH}$ neuron excitability and hormone secretion. Nat Commun 2016;7: 10055.

111 McCartney CR, Marshall JC: Neuroendocrinology of Reproduction; in Strauss JF, Barbieri RL (eds): Yen and Jaffe's Reproductive Endocrinology: Physiology, Pathophysiology, and Clinical Management, ed 7. Philadelphia, PA: Elsevier Saunders; 2014, pp 3-26. 
112 Murphy AA, Kettel LM, Morales AJ, Roberts VJ, Yen SS: Regression of uterine leiomyomata in response to the antiprogesterone $\mathrm{RU}$ 486. J Clin Endocrinol Metab 1993;76:513517.

113 Murphy AA, Morales AJ, Kettel LM, Yen SS: Regression of uterine leiomyomata to the antiprogesterone RU486:dose-response effect. Fertil Steril 1995;64:187-190.

114 Kettel LM, Murphy AA, Morales AJ, Ulmann A, Baulieu EE, Yen SS: Treatment of endometriosis with the antiprogesterone mifepristone (RU486). Fertil Steril 1996; 65:23-28.

115 Garrido-Gracia JC, Bellido C, Aguilar R, Sánchez-Criado JE: Protein kinase C cross- talk with gonadotrope progesterone receptor is involved in $\mathrm{GnRH}$ induced $\mathrm{LH}$ secretion. J Physiol Biochem 2006;62:35-42.

116 Spitz IM, Bardin CW: Mifepristone (RU 486) - a modulator of progestin and glucocorticoid action. N Engl J Med 1993;329:404412.

117 Deng Q, Riquelme D, Trinh L, Low MJ, Tomić M, Stojilkovic S, Aguilera G: Rapid glucocorticoid feedback inhibition of ACTH secretion involves ligand-dependent membrane association of glucocorticoid receptors. Endocrinology 2015;156: 3215-3227.

118 Dumesic DA, Schramm RD, Bird IM, Peterson E, Paprocki AM, Zhou R, Abbott DH:
Reduced intrafollicular androstenedione and estradiol levels in early-treated prenatally androgenized female rhesus monkeys receiving follicle-stimulating hormone therapy for in vitro fertilization. Biol Reprod 2003;69:1213-1219.

119 Chang RJ, Cook-Andersen H: Disordered follicle development. Mol Cell Endocrinol 2013;373:51-60.

120 Walker ML: Menopause in female rhesus monkeys. Am J Primatol 1995;35: 59-71.

121 Downs JL, Urbanski HF: Neuroendocrine changes in the aging reproductive axis of female rhesus macaques (Macaca mulatta). Biol Reprod 2006;75:539-546. 